\title{
A REIVINDICAÇÃO DA EXTENSÃO DA PLATAFORMA CONTINENTAL BRASILEIRA
}

\author{
Catarina de Almeida Burlina* \\ Barbara Mourão Sachett**
}

\section{RESUMO}

Os Estados costeiros e os Estados Sem Litoral contêm direitos e deveres em um determinado espaço no oceano, visto ser um ambiente cheio de recursos que contribuem no desenvolvimento das sociedades, como o petróleo, o pré-sal, o ouro. Mediante essas descobertas, se fez necessária a constituição de leis que regulassem a utilização desses espaços de forma igualitária para todos os Estados, e essa regulamentação ficou conhecida como a Convenção das Nações Unidas sobre o Direito do Mar - CNUDM, estabelecendo faixas marítimas com jurisdição nacional, tais como, Mar Territorial, Zona Contígua, Zona Econômica Exclusiva (ZEE) e Plataforma Continental, cada uma das faixas marítimas contém respectivos direitos e deveres que todos os Estados Costeiros e os Estados sem Litoral signatário à Convenção devem respeitar. Na Plataforma Continental, o Estado brasileiro contém direitos de exploração e aproveitamento dos recursos existentes, porém esses direitos se limitam da costa que se estende em até 200 milhas marítimas mar adentro e para a ampliação jurídica desta é fundamental instituir, procedimentos a serem seguidos e aprovados por uma Comissão de Limite da Plataforma Continental (CLPC).

Palavras-chave: Oceano; Faixas Marítimas; Recursos; Convenção das Nações Unidas; Ampliação.

\section{THE CLAIM OF THE BRAZILIAN CONTINENTAL SHELF}

\section{ABSTRATC}

Coastal States and Land-locked States contain rights and duties in a given space in the ocean, since it is an environment full of resources that contribute to the development of societies, as well as oil, pre-salt and gold. Through these discoveries, it became necessary to establish laws regulating the use of these spaces in an equal manner for all States, and these regulations became known as the United Nations Convention on the Law of the Sea (UNCLOS), establishing maritime stripes with national jurisdiction, such as Territorial Sea, Contiguous Zone, Exclusive Economic Zone (EEZ) and Continental Shelf, each of the maritime strips contains respective rights and duties that all Coastal States and the Land-locked States signatory to the Convention must respect. In the Continental Shelf, the Brazilian State contains exploration ri-

* Bacharel em Direito na Universidade Metodista de São Paulo-UMESP, com endereço de e-mail catarinaburlina@hotmail.com.

** O presente trabalho resultou com a orientação da Professora Mestra na Universidade Metodista de São Paulo-UMESP Barbara Mourão Sachett. barbara.sachett@metodista.br 
ghts and exploitation of existing resources, but these rights are limited to the coast extending up to 200 nautical miles inland and for legal expansion of the same, it is essential to establish procedures to be followed and approved by a Continental Shelf Limit Commission (CLPC).

Keywords: Ocean; Maritime Bands; Resources; United Nations Convention; Enlargement.

\section{INTRODUÇÃO}

Foi um longo processo de tentativas até ser consolidada a regulamentação aos Estados sobre o uso do mar. As tentativas que ocasionaram a regulação de forma Internacional foram as Conferências das Nações Unidas sobre o Direito do Mar-CNUDM (United Nations Conference on the Law of the Sea - UNCLOS), em que somente com a Terceira Conferência foram tratados todos os pontos pendentes das conferências anteriores, sendo formalizado e aprovado no dia 10 de novembro de 1982, em Montego Bay, Jamaica, porém, sua vigência nos Estados signatários, dentre eles o Brasil, se deu, apenas no dia 16 de novembro de 1994.

Com a vigência da Convenção das Nações Unidas sobre o Direito do Mar em 1982, foi estabelecida a divisão, bem como a extensão, de faixas marítimas que se encontram sob a soberania de cada Estado costeiro e com alguns direitos definidos aos Estados Sem Litoral, sendo assim dividido em Mar Territorial, Zona Contígua, Zona Econômica Exclusiva (ZEE) e Plataforma Continental. Diante da delimitação das faixas marítimas, a Marinha do Brasil as conceituou, de forma geral, como Amazônia Azul, visto seu tamanho ser equiparado à floresta amazônica, no Atlântico Sul.

No fundo dessa imensidão azul, nos são proporcionadas riquezas, das quais boa parte estão localizadas nos limites da Zona Econômica Exclusiva (ZEE), como o petróleo, o gás natural e o Pré-sal, bem como a biodiversidade.

O Estado, em cada espaço marítimo, detém direitos e deveres, quanto ao aproveitamento e preservação dos recursos neles contidos, ou seja, cada faixa marítima contém suas particularidades.

Diante da descoberta da diversidade dessas riquezas que o mar contém, o Brasil, em 2004, apresentou um projeto para a ampliação da plataforma continental, por meio do Plano de Levantamento da Plataforma Continental Brasileira (LEPLAC) para a ONU, porém, a Comissão ao analisar o projeto, aprovou em parte os acréscimos que foram solicitados, mas diante do inconformismo, o Brasil decidiu formular outro LEPLAC para que a aprovação do projeto fosse integral, sendo assim, reavaliou as medidas e extensões de cada espaço para a sua reivindicação.

O presente trabalho pretende expor a importância da soberania marítima brasileira, e a sua defesa diante dos demais Estados, a partir da sua costa até um determinado espaço no mar, que é dividido em faixas marítimas, sendo que em cada delimitação há direitos e deveres a serem exercidos e respeitados pelo Estado ribeirinho. 


\section{CONSTITUIÇÃO DOS OCEANOS}

A necessidade de se estabelecer um regime jurídico quanto ao aproveitamento dos recursos existentes e a navegação nos oceanos pelos Estados, a partir das costas adiante, foi se consolidando ao longo de um processo de preocupação econômica, de preservação ambiental e de inseguranças que, por esse último, poderia ocasionar guerras.

Um marco importante que desencadeou as discussões quanto ao uso dos mares pelos Estados no Direito Internacional Clássico ficou conhecido como Mar Fechado (Mare Clausum) e Mar Aberto (Mare Liberum) por volta do final do século XVI e início do século XVII, ambos os termos tratavam do direito de navegação sob as novas rotas marítimas, conforme explica Zanella:

Descoberto o caminho para a Índia e a chegada à América, os portugueses começaram a reivindicar a soberania sobre os mares descobertos. Portugal tornou-se um império de rotas e entrepostos, fundamentado em alguns homens e mercadorias de ponta, tornando-se necessário o domínio dos mares para assegurar sua condição de potência mercantil (ZANELLA, 2017, p. 56).

Assim, o Estado que descobrisse novas rotas marítimas para navegação e expansão do seu comércio, poderiam impor sua soberania e os demais Estados deveriam respeitar, ou seja, estariam limitados à navegação das rotas descobertas pelos Portugueses.

Ademais os Estados passaram a contestar tal costume, tendo como consequência a publicação da obra Mare Liberum por Hugo Grócio, como expõe Zanella:

Em sua tese, Grócio defendia que o mar é coisa comum, insuscetível de apropriação, e que a sua utilização deve ser livre, principalmente para a navegação. Para o autor, o direito natural da comunicação é uma exigência da sociabilidade humana: já o domínio estatal sobre uma faixa do mar é possível (ZANELLA, 2017, p. 60).

Por fim, prevaleceu a teoria do Mar Aberto, sendo assim direito de todos os Estados a navegação livre em todas as rotas marítimas.

Porém, as inseguranças eram imensas, pois receavam futuras discórdias quanto às navegações entre os Estados Costeiros que poderiam ocasionar guerras, assim, o autor Trindade (2003) explica, os Estados começaram a delimitar a soberania marítima pela distância de um tiro de canhão, que equivale a 3 milhas náuticas, sendo esse espaço denominado Mar Territorial, e para além dessa delimitação, entendia-se o alto-mar, ou seja, os Estados não poderiam impor sua soberania jurídica nesse espaço marítimo.

Contudo, até o momento, as discussões se consagravam tão-somente na parte superior dos oceanos, como assevera Trindade. 
[...] O Direito do Mar Clássico, de base consuetudinária, definia o regime jurídico do mar com um enfoque voltado essencialmente à navegação sobre a superfície marítima, ignorando-se outros aspectos como aqueles relativos aos fundos marinhos e oceânicos, de tal maneira que se fala no Direito do Mar Clássico como o direito de um mar "unidimensional" ou "unifuncional" (TRINDADE, 2003, p. 41/42 - grifos do autor).

Dessa forma, entende-se que os Estados, a princípio, se encontravam mais preocupados com atividades que exigiam a utilização da superfície do mar, solicitando um regimento que regulasse, com foco no uso dos mares na parte superior, a navegação e a pesca, sendo assim o aproveitamento dos recursos que se encontravam no solo e subsolo do mar não seriam tratados nesse momento.

Portanto, as descobertas e a importância do aproveitamento das riquezas no leito e subsolo marinho, se realizaria mais à frente, especificamente na metade do século XX, e acarretaria também um marco importante feito pela declaração do presidente Harry Truman, que precedeu a elaboração das três Conferências das Nações Unidas sobre o Direito do mar, como explica Trindade:

Em 1945, o presidente estadunidense Harry Truman declarou parte do território dos EUA a plataforma continental adjacente ao território terrestre, com o argumento de que se tratava de seu prolongamento geográfico. A Declaração Truman não sofreu oposição significativa e vários outros Estados foram progressivamente incorporando suas próprias plataformas continentais (TRINDADE, 2003, p. 43).

Portanto, diante dos acontecimentos, refletiu-se a importância e a necessidade da elaboração de um texto que indicasse a regulação de forma internacional, ou seja, para todos os Estados signatários, dando origem à primeira Conferência das Nações Unidas sobre o Direito do Mar - CNUDM (First United Nations Conference on the Law of the Sea) - UNCLOS I) elaborada em Genebra, no ano de 1958, mas com um contexto limitado, devido à não abrangência de todos os aspectos necessários que deveriam ter sido discutidos, como explica Menezes:

[...] a Primeira Convenção das Nações Unidas sobre Direito do Mar, que reuniu entre os meses de fevereiro e abril daquele ano e teve participantes de 86 estados, resultando na celebração de quatro convenções sobre o Direito do Mar: 1) mar territorial e zona contígua; 2) plataforma continental; 3) alto-mar; e 4) pesca e conservação dos recursos vivos do alto mar.[...] Cabe destacar, entretanto, a ausência do acordo sobre a extensão do mar territorial a mais de três milhas, ou sobre o estabelecimento de direitos exclusivos de pesca fora de tal espaço. Apesar disso as quatro convenções entraram em vigor nos anos 1960 (MENEZES, 2015, p.30).

Com a elaboração do texto da Primeira Conferência da CNUDM em 1960, surgiram diversas oposições por parte de alguns Estados, acarretando como consequência a convocação da Segunda Conferência das Nações Unidas sobre Direito 
do Mar (Second United Nations Conference on the Law of the Sea - UNCLOS II) a qual, de acordo com Trindade (2003), se deu entre os dias 17 de março e 27 de abril, em Genebra, no mesmo ano da elaboração do texto da Primeira Conferência, em 1960, porém alguns pontos importantes não chegaram a ser resolvidos novamente, restando ainda pontos pendentes, dando origem, assim, à convocação da Terceira Conferência das Nações Unidas (Third United Nations Conference on the Law of the Sea - UNCLOS III).

A Terceira Conferência teve longas negociações e discussões pelos Estados, até ser consolidado e votado, como assevera Trindade:

O resultado dessa votação, ocorrida em 30 de abril de 1982, foi a aprovação do texto final da Convenção das Nações Unidas sobre Direito do Mar por 130 votos a favor contra 4 votos contrários, além de 18 abstenções e de 18 votos não registrados (TRINDADE, 2003, p. 64).

Portanto, o texto da Terceira Conferência das Nações Unidas (Third United Nations Conference on the Law of the Sea - UNCLOS III) foi aprovado em 1982, mas somente entrou em vigor no dia 16 de novembro de 1994, sendo definidos os espaços do oceano que contém jurisdição nacional, ou seja, os fundos marinhos e o subsolo dentre outros pontos, que até então não estavam previstos na Primeira e na Segunda Conferência das Nações Unidas sobre o Direito do Mar (First and Second United Nations Conference on the Law of the Sea - UNCLOS I and II).

\section{AMAZÔNIA AZUL}

Nesse tópico analisaremos cada espaço marítimo estabelecido ao Estado costeiro pela CNUDM, porém, antes serão indicados alguns princípios importantes para o Direito do Mar, dentre eles, o princípio do Patrimônio Comum da Humanidade, como conceituam Letícia Albuquerque e Januário Nascimento:

[...] De acordo com os civilistas, patrimônio pode ser definido como o conjunto de todos os direitos e obrigações suscetíveis de avaliação pecuniária de que cada pessoa é titular. O patrimônio comum da humanidade é um princípio geral do direito emergente. A noção de patrimônio comum da humanidade submeterá a área fora das jurisdições estatais a um regime internacional (ALBUQUERQUE; NASCIMENTO, [2002], p. 137).

Dessa forma, entendemos que o conceito de Patrimônio Comum da Humanidade, se refere ao Mar como um espaço de direito universal.

Ademais, discorremos referente ao princípio da igualdade e da solidariedade, pois identificamos esse princípio desde o momento da votação na CNUDM, como também em relação aos Estados Interiores, em outras palavras, os Estados sem Litoral, como segue a explicação de Letícia Albuquerque e Januário Nascimento: 
Estados sem litoral terão o direito a participar, numa base equitativa, no aproveitamento de uma parte dos excedentes dos recursos vivos das zonas econômicas exclusivas dos Estados costeiros da mesma sub-região ou região. É o caso de Países sem litoral como a Suíça e a Áustria que possuem uma frota e aproveitam dos recursos da ZEE de outros Países (ALBUQUERQUE; NASCIMENTO, [2002], p. 140).

Deste modo, vemos que a Convenção tentou estabelecer a igualdade e a solidariedade dos Estados no uso e aproveitamento dos solos marinhos para os Estados que não têm litoral, ou seja, não obtendo estes acessos aos mares.

Outro princípio importante é o Princípio do Benefício para a Humanidade, segundo o qual toda atividade realizada na área deve ser exercida para o bem de todas as nações.

Encontramos também o Princípio da Proteção da Vida Humana, conforme expõe Menezes:

Os Estados devem adotar normas, regulamentos e procedimentos apropriados que estejam em consonância com a Declaração Universal dos Direitos Humanos e com os diversos tratados que tangenciem a matéria, disciplinando mecanismos que observem tais valores na utilização da área (MENEZES, 2015, p. 155).

Em sequência, o princípio da soberania, sendo esse também muito importante para o Direito do Mar, pois é tratado a todo momento pelas Conferências, como observam Albuquerque e Nascimento:

O princípio de soberania esteve presente em todas as Conferências sobre o Direito do Mar e nas legislações internas. Por exemplo, o Decreto/ lei n. ${ }^{\circ} 1.098$ apresentou afirmação unilateral de soberania para o necessário lastro jurídico à nação brasileira contra eventuais incursões estrangeiras. Um de seus considerandos falou em "exercício de soberania inerente ao conceito de mar territorial" o qual se estende "ao espaço aéreo acima do mar territorial, bem como ao leito e subsolo do mar (ALBUQUERQUE; NASCIMENTO, [2002], p. 131).

Portanto, para que se pudesse consolidar leis que regulassem o uso dos mares, de forma justa e válida para todos os Estados Signatários, foi necessário embasar-se em leis consuetudinárias e nos princípios anteriormente mencionados.

Partiremos agora para a explicação dos espaços marítimos, sendo alguns deles resultados de grandes controvérsias, como o Mar Territorial.

O Mar Territorial, como mencionado no primeiro item, teve sua delimitação estabelecida mediante costumes internacionais a longo prazo e diversas discussões, pois a princípio a sua extensão equivalia a um tiro de canhão, porém, com o tempo foi necessário determinar uma distância maior, com foco em garantir a igualdade entre os Estados Costeiros. 
Assim, como explica Zanella (2017) mediante a CNUDM ficou estabelecida a extensão do Mar Territorial pela distância em até 12 milhas náuticas para cada Estado Costeiro, porém, essa delimitação pode ser relativa em alguns casos, ou seja, com algumas exceções, que podem variar para mais ou para menos.

Diante disso, para os casos da extensão do Mar Territorial para além de 12 milhas náuticas, Zanella explica:

Quando estes ancoradouros, utilizados habitualmente para carga, descarga, fundamento ou amarração de embarcações, situam-se além do limite máximo de 12 milhas náuticas estipuladas para Mar Territorial, são considerados pela prática e pela convenção como integrantes deste espaço. Nestas Situações, amplia-se a orla exterior do Mar Territorial (a fim de englobar os ancoradouros) e ignora-se a regra do paralelismo com as linhas de base (ZANELLA, 2017, p. 151).

E para os casos em que a extensão do Mar Territorial é inferior à 12 milhas náuticas, Zanella expõe o seguinte caso:

A outra circunstância na qual a largura da referida zona é relativizada é nos casos em que as costas de dois Estados concorrem frente a frente e a distância entre elas é inferior a 24 milhas, ou seja, teoricamente, o Mar Territorial de um País se sobrepõe ao de outro (ZANELLA, 2017, p. 151).

Essa delimitação de até 12 milhas náuticas atinge de forma internacional todos os Estados, contudo, também é relativa, devido a diversas circunstâncias geográficas, como exposto pelo autor.

Com a consolidação das Leis estabelecidas pela CNUDM em 1982, o Estado Costeiro detém soberania sobre essa faixa marítima, o Mar Territorial, mas não é uma soberania total, conforme explica Zanella:

Posteriormente, a CNUDM aplicou, fundamentalmente da mesma forma que a Convenção de 1958, a teoria da soberania limitada. [...] Assim, ambas as Convenções, consagraram a natureza jurídica do Mar Territorial como um espaço sujeito à soberania do Estado Costeiro. Contudo, essa soberania não é ilimitada, além de gozar desta prerrogativa exclusiva, o Estado ribeirinho está sujeito a certas obrigações e os demais países também detêm alguns direitos sobre este espaço (ZANELLA, 2017, p. 161).

Assim, entende-se que o Estado costeiro detém soberania sobre o Mar Territorial, sendo possível a aplicação da jurisdição nacional, mas com algumas exceções, como por exemplo, o Direito de Passagem Inocente ou Inofensiva. ${ }^{1}$

1 Navegação estrangeira rápida e continua em Mar Territorial do Estado Costeiro, exceto em casos infortúnios. 
A faixa marítima seguinte é a Zona Contígua, como conceitua Mazzuoli:

\begin{abstract}
Entende-se como zona contígua a faixa do alto - mar que se inicia-se imediatamente após o limite do mar territorial, e em princípio de mesma largura, sobre a qual o Estado Costeiro tem o direito de tomar medidas de fiscalização que julgar convenientes na defesa de seu território, exercendo o necessário controle no sentido de prevenir ou punir infrações aos seus regulamentos aduaneiros, fiscais, sanitários, de imigração e de segurança, que tenham sido tais infrações cometidas em seu domínio terrestre ou no mar territorial (MAZZUOLI, 2014, p. 842).
\end{abstract}

Portanto, o Estado Costeiro não exerce poder de soberania na Zona Contígua, somente poder de fiscalização e de vigilância. Como assevera Mazzuolli (2014) a delimitação da respectiva zona é de até 12 milhas náuticas a partir da linha de base, posterior ao mar territorial, compreendendo-se, assim, 24 milhas náuticas a partir da linha de base do Mar Territorial.

Posterior à Zona Contígua, nos deparamos com a terceira faixa marítima, a Zona Econômica Exclusiva (ZEE) ou também conceituada como Zona de Pesca.

O seu conceito e delimitação podem ser encontrados a partir do direito consuetudinário, visto que as discussões e a dada importância a respeito do uso da respectiva faixa marítima surgiram muito antes da aprovação da CNUDM.

A menção a respeito da Zona Econômica Exclusiva (ZEE) que culminou futuras reivindicações por demais países, se deu mediante a declaração realizada pelo Presidente Harry Truman, como explica Zanella:

[...] o mais importante ato para criação desse espaço marítimo ocorreu em 1945 com a Proclamação Truman. Como vimos, o presidente norte americano Harry Truman assinou um documento unilateral instituindo uma zona marítima na qual os Estados Unidos exerceriam direitos exclusivos relativos à gestão, regulação e controle dos recursos da pesca (ZANELLA, 2017, p. 228).

Podemos então entender, de início, que o reconhecimento da importância dessa área marítima voltava-se mais à atividade da pesca, por isso estabelecida também a denominação de Zona de Pesca.

Com a CNUDM, conforme explica Zanella (2017) ficou estabelecida a extensão da Zona Econômica Exclusiva (ZEE) de até no máximo 200 milhas náuticas, sendo que para os Estados Costeiros que contém Mar Territorial, compreende-se de 188 milhas náuticas à respectiva zona com as 12 milhas marítimas do Mar Territorial.

O autor (2017) explica, ainda, as atividades que os Estados Costeiros poderão exercer como explorar e aproveitar os recursos naturais, além das demais atividades com fins econômicos.

A Convenção não deixou olvidar a respeito de seu regime jurídico, estabelecendo para tal um regime próprio, com liberdades e restrições, porém em alguns aspectos os regimes estabelecidos ao Mar Territorial e ao Alto-Mar também são 
aplicáveis à Zona Econômica Exclusiva (ZEE), mas não se sobrepõem ao que está regulamentado propriamente à Zona Econômica Exclusiva (ZEE), ou seja, não deve haver conflito entre as normas estabelecidas à Zona Econômica Exclusiva (ZEE) com o regime jurídico do Alto Mar e do Mar Territorial, quando assim forem aplicados, como explica Zanella a respeito da semelhança na aplicação ao Alto-Mar:

Se por um lado, os direitos exclusivos, sobre os recursos naturais do Estado costeiro em ZEE não se confunde com o regime de liberdades imposto ao alto mar; por outro, para determinados fins em especial para a navegação a ZEE se assemelha e absorve características e alto-mar. A própria CNUDM afirma no artigo 58, que as regras e liberdades inerentes ao alto mar se aplicam a ZEE, se não forem incompatíveis com seu regime. Ou seja, retirando as liberdades e restrições impostas à ZEE, aplica-se o regime jurídico do alto mar, com todas as suas liberdades de navegação (ZANELLA, 2017, p. 238).

Entende-se que a aplicação do regime jurídico do Alto Mar à Zona Econômica Exclusiva (ZEE) é restrita, pois deve ser respeitada a legislação própria da respectiva faixa.

E quanto à aplicação do regime jurídico do Mar Territorial à Zona Econômica Exclusiva (ZEE) Zanella afirma:

[...] são os poderes de soberania sobre a exploração dos recursos naturais e aproveitamento para qualquer finalidade econômica, além dos direitos e deveres de conversação e proteção do meio marinho. Ou seja, retirando as liberdades e restrições específicas impostas à ZEE, aplica-se o regime jurídico do Alto Mar, com todas as suas liberdades de navegação (ZANELLA, 2017, p. 239).

Portanto, a aplicação do regime jurídico tanto do Mar Territorial quanto do Alto Mar somente se aplica à Zona Econômica Exclusiva (ZEE) quando não colidir com o regime próprio desta ou se não houver legislação sobre alguns pontos.

A Convenção também tratou da jurisdição nacional nos fundos marinhos, que ficou conhecido como Plataforma Continental, esta que se compreende como uma extensão territorial do Estado Costeiro, abaixo das águas oceânicas, em até 200 milhas náuticas, a partir da linha de base do Mar Territorial, como conceitua Zanella:

[...] o território de um Estado normalmente se prolonga mar adentro e não desaparece de imediato com os oceanos. Este prolongamento natural, cuja profundidade varia de 130 a 200 metros em média, se denomina Plataforma Continental. Após este, tem-se início o talude continental (também denominado de escarpa continental ou rebordo oceânico (ZANELLA, 2017, p. 289).

Contudo, dada a importância da respectiva faixa marítima, que somente findou no século XX, como já mencionado no item anterior, pela Proclamação do 
Presidente norte-americano Truman, esta teve como sequência a reivindicação dos demais Estados:

Foi o que ocorreu em 1945 com a já citada Proclamação Truman do presidente norte americano. Nesta, os EUA afirmavam que o solo e subsolo da costa estadunidense, correspondente à Plataforma Continental, faziam parte do prolongamento terrestre do país e, por conseguinte, detinham direitos de jurisdição e exploração (ZANELLA, 2017, p.291).

A Proclamação do Presidente norte americano atuou como uma grande influência nos Estados, inclusive para o Brasil.

Zanella (2017, p.292) afirma que, "o Brasil instituiu unilateralmente seus direitos sobre esta zona em 1950, por meio do Decreto n. 28.840 em 08 de novembro daquele ano".

A Convenção estabeleceu que a extensão da Plataforma Continental se compreende em até 200 milhas Náuticas para cada Estado Costeiro, mas pode ser relativa, devido à extensão da Plataforma Continental de cada Estado.

Contudo, a Convenção estabeleceu dois critérios que podem ser seguidos, o primeiro critério quanto à distância:

No primeiro caso, instituiu a CNUDM, que os Estados costeiros possuem legítimos direitos de exploração do leito e subsolo marinho até 200 milhas marítimas a contar da linha de base, independentemente das características do solo e do subsolo. Assim, quando não possui uma Plataforma Continental geográfica até a referida distância, o Estado ribeirinho pode estender até as 200 milhas seus direitos de exploração (ZANELLA, 2017, p. 296).

Portanto, aos Estados Costeiros que contém a extensão da sua Plataforma Continental inferior a 200 milhas náuticas, ou seja, o prolongamento de seu território adentro ao oceano não chega a medir 200 milhas marítimas, mesmo assim, pode-se entender que, contém direitos de exploração para até a extensão que compreenda 200 milhas náuticas como de direito.

Em relação ao segundo critério, da formação geomorfológica, como Zanella (2017, p. 296) afirma como, “[...] mencionado, o Estado tem o direito de ocupar o espaço que vai das 200 milhas marítimas até o extremo da margem continental da Plataforma geomorfológica (no máximo até 350 milhas)".

E para os Estados Costeiros que contém o prolongamento territorial para além de 200 milhas marítimas, como o caso do Brasil, pode ser calculado a partir de dois critérios:

A primeira chama-se fórmula irlandesa, também apelidada de fórmula Gardiner [...] i), ao destaca que o limite exterior será traçado onde a "espessura das rochas sedimentares seja pelo menos 1\% da distância da mais curta entre o ponto e o pé do talude ${ }^{2}$ continental

2 Terreno inclinado. 
[...] ii) este limite deverá estar situado " a não mais de 60 milhas marítimas do pé do talude continental". A chamado fórmula de Hedberg sugere esta distância tendo em consideração a dificuldade em determinar com precisão o local onde se encontra o pé do talude continental (ZANELLA, 2017, P. 297).

Por fim, a Convenção das Nações Unidas sobre o Direito do Mar conceitua a Plataforma Continental:

[...] A CNUDM destacou que a Plataforma Continental compreende "os recursos minerais e outros recursos não vivos do leito do mar e subsolo bem como os organismos vivos pertencentes a espécies sedentárias, isto é, aquelas que no período de captura estão imóveis no leito do mar ou no seu subsolo ou só podem mover-se em constante contato físico com esse leito ou subsolo" (ZANELLA, 2017, p. 295).

Assim, o Estado Costeiro contém alguns direitos no respectivo espaço marítimo, este que é voltado somente para a exploração e aproveitamento dos recursos assim disponíveis.

\section{GUERRA DA LAGOSTA}

Na década de sessenta, o Brasil se viu diante de um conflito com a França que, por pouco, não ocasionou uma guerra ${ }^{3}$ entre ambos os Estados por causa de um crustáceo, a lagosta. Conforme explica Zanella:

Os barcos pesqueiros franceses, em 1961/62, virem para a costa nordestina do Brasil para explorar este recurso vivo marinho. Os lagosteiros estrangeiros realizavam esta exploração a cerca de 40 milhas marítimas das linhas de base nacional. Ou seja, esta pesca era efetuada fora dos limites das águas jurisdicionais brasileiras, que na época correspondiam a 3 milhas de Mar Territorial e 12 milhas de Zona Contígua (ZANELLA, 2017, p. 312).

Porém, conforme já tratado no segundo item, a respeito da Proclamação do Presidente norte americano Truman e a reivindicação da Plataforma Continental Brasileira em 1950, de forma unilateral, os navios pesqueiros franceses estavam pescando a lagosta de forma ilegal, visto que se localizavam em uma zona com jurisdição nacional brasileira.

Assim, como expõe Zanella (2017) em 02 de janeiro de 1962 começaram a

3 Para mais informações, segue o link do depoimento de um homem que participou do respectivo conflito armado entre Brasil e França, como operador de rádio: https://www.youtube.com/watch?v=RKJULZNnlfQ 
ocorrer as apreensões dos navios pesqueiros franceses, pois o Brasil alegava que os recursos encontrados na respectiva faixa marítima, eram de direito dele, e a França deveria solicitar uma autorização para a prática da pesca, mas os franceses entendiam de outra forma:

O principal argumento era de que este crustáceo não era uma espécie sedentária. Em outros termos, os franceses afirmavam que as lagostas não se enquadravam tecnicamente na definição de espécies sedentárias pertencentes à Plataforma Continental. [...] Essa argumentação francesa era fundamentada na característica da lagosta de se deslocar através de saltos e não andando sobre o leito oceânico. Sendo assim, consideravam que esta espécie possuía características natatórias, como um peixe (ZANELLA, 2017, p. 314).

Em contrapartida, o comandante brasileiro Paulo de Castro Moreira da Silva respondeu, conforme expõe Zanella:

Ela se deslocava de um lado para o outro dando saltos e não andando. Sendo assim, deveriam ser consideradas como peixes e, como tais, passíveis de serem pescados por não pertencerem â Plataforma Continental. Ora, estamos diante de uma argumentação interessante: por analogia, se a lagosta é um peixe porque se desloca dando saltos, então o canguru é uma ave (ZANELLA, 2017, p. 314)

Por fim, o Ministério das Relações Exteriores (MRE), mediante as conversas, discussões e estudos jurídicos, deu razão ao Brasil, declarando que a lagosta se inclui como um recurso vivo na Plataforma Continental, restando a conclusão de que a respectiva pesca era ilegal.

O Presidente Goulart, que à época ocupava o respectivo cargo da República Federativa do Brasil, para apaziguar os ânimos, decidiu o seguinte:

No início de 1963, o presidente Goulart resolveu autorizar, em caráter excepcional, que seis embarcações francesas que já se encontravam na costa do nordeste brasileiro continuassem a capturar os crustáceos. [...] Porém, destacou Goulart que somente com assinatura de um acordo Brasil-França o Governo permitiria a exploração contínua das lagostas na Plataforma Continental Brasileira (ZANELLA, 2017, p. 320).

Tal autorização não foi de conformidade total para os brasileiros que praticavam a atividade da pesca na região, mesmo assim a autorização prosseguiu para os franceses.

Contudo a respectiva autorização não se prolongou muito, sendo cancelada no mesmo ano pelo respectivo Presidente, mediante um acontecimento quase que trágico entre os navegantes pesqueiros brasileiros e franceses:

[...] após um incidente em que um pesqueiro francês abalroou uma jangada, quase causando a morte do brasileiro, o jornal Correio da Manhã 
estampou a manchete: "Navios franceses atacam no Nordeste jangadeiros que pescam lagosta". Ainda, descobriu-se que os estrangeiros estavam utilizando a técnica de arrasto para a captura dos crustáceos, causando enorme devastação ambiental. Estas redes são proibidas para a pesca da lagosta em todas as áreas produtoras, pois exterminam as espécies sedentárias, não poupando nem as menores nem as ovadas. Ainda o arrasto levava consigo todos os covos depositados pelos brasileiros (ZANELLA, 2017, p. 321).

Além do incidente que resultou quase na morte de um brasileiro, os franceses estavam prejudicando as espécies e recursos marinhos do Brasil, por sua forma de pescar, como explica Zanella (2017).

Mas o Presidente francês General Charles de Gaulle não se conformou com o cancelamento da pesca e realizou uma reunião com o Embaixador brasileiro em Paris em que declarou a seguinte frase, tão conhecida: "Le Brésil n`est pás um pays serieux ": "O Brasil não é um país sério".

Posteriormente a essa reunião, o Presidente da França, ainda inconformado com a decisão do Presidente Goulart, enviou um navio de guerra no local onde os seis navios pesqueiros franceses se localizavam na Plataforma Continental Brasileira:

De Gaulle resolveu então enviar um navio de guerra, o contratorpedeiro
Tartu a fim de proteger os lagosteiros franceses ao largo da costa nordes-
te brasileiro. O envio dessa embarcação de guerra foi motivo de grande
mobilização das forças armadas nacionais. O Brasil suspendeu todas as
negociações com a França e exigiu a retirada imediata do navio de guer-
ra, a qual foi negada pelo Governo Francês (ZANELLA, 2017, p. 322).

Diante das práticas dos franceses, o Brasil precisou se armar contra aqueles, com suas aeronaves e navios de guerra, enviando-os para a região onde se encontravam os navios pesqueiros franceses e o Contratorpedeiro Tartu. Mas, em posição de desvantagem, como assevera Zanella (2017) a quantidade de munição que o Brasil detinha frente ao poderio francês era muito pequena, visto que somente teria munição para combater trinta minutos.

Diante da situação do Brasil com a França, os Estados Unidos da América resolveram intervir:

[...] o Embaixador dos EUA comunicou o Comandante da Marinha (CEMA) de que os Contratorpedeiros Paraná e Pernambuco deveriam regressar imediatamente. O embaixador recebeu um memorando informando-o da existência de uma Lei do Senado estadunidense que proibia a utilização de qualquer artefato bélico produzido nos EUA contra um aliado americano no caso a França. Ocorre que os Contratorpedeiros haviam sido adquiridos do exército americano (ZANELLA, 2017, p. 323).

Zanella transcreve, que em resposta ao embaixador dos EUA, o comandante da marinha escreveu o seguinte: 
[...] O Brasil honrou o seu compromisso assumido por ocasião da Conferência de Havana em 1940, onde se declarou que um ataque por um Estado não americano contra qualquer Estado americano é considerado como ataque contra todos os Estados americanos. Sabemos que os EUA têm compromissos políticos e militares com a França em virtude do Tratado Atlântico Norte, firmado em 1949. Entretanto, antes desse Tratado, os EUA em 1947, nesta cidade do Rio de Janeiro, lideraram a assinatura do Tratado Interamericano de Assistência Recíproca (TIAR), que teve como propósito prevenir e reprimir as ameaças e atos de agressão a qualquer dos países da América. Assim sendo, configurada a agressão francesa, como anunciado em Paris, o Brasil espera que os EUA honrem os seus compromissos na defesa coletiva do continente americano declarando guerra contra a França, como o Brasil honrou seus compromissos declarando guerra aos japoneses na 2 Guerra Mundial, sem nunca ter sido agredido por eles (ZANELLA, 2017, p. 324).

A decisão do Brasil em enviar as aeronaves e os navios de guerra prosseguiram ao encontro dos franceses.

Felizmente, não ocorreu conflito armado entre os Estados, mas como explica Zanella (2017) o governo da França decidiu trocar o seu Contratorpedeiro Tartu por um navio de guerra menor, o Aviso Paul Goffeny, que, se manteve no local do anterior.

Por fim, no dia 04 de março de 1963, o Governo da França decidiu por retirar o seu navio de guerra da Zona Marítima Brasileira, findando assim, a conflito armado conhecido como a Guerra da Lagosta.

\section{O PLANO DE LEVANTAMENTO DA PLATAFORMA CONTINEN- TAL BRASILEIRA (LEPLAC)}

A extensão da Plataforma Continental Brasileira pode ser relativa, pois para alguns Estados Costeiros a Plataforma Continental não chega a 200 milhas marítimas e outras Plataformas Continentais chegam a ter uma distância superior a 200 milhas.

No caso da Plataforma Continental brasileira, a sua extensão é superior a 200 milhas marítimas, sendo assim passível de reivindicação para estender além desse limite, portanto, o aproveitamento dos recursos ali existentes estariam sob jurisdição nacional brasileira e para os demais países somente mediante autorização concedida pelo Brasil.

Porém, essa reivindicação conforme explica Zanella (2017) assim concedida, somente passaria a alcançar até 350 milhas marítimas, ou seja, a Plataforma Continental que mede 200 milhas, passaria a medir 350 milhas.

Para reivindicar a sua extensão, é necessário seguir procedimentos, estes explicados por Zanella:

[...] Finalmente, o modo de delimitação desta zona para além das 200 milhas funciona, na prática, da seguinte forma: o Estado costeiro faz um estudo para delimitar o que entende ser a sua Plataforma Continental, utilizando as regras estabelecidas pela CNUDM. [...] Feito isto, é apre- 
sentado à Comissão de limites da Plataforma Continental, composta por 21 membros, que analisará os dados científicos e votará o pedido do Estado. Se a maioria qualificada de dois terços entenderem pela procedência do pedido, fica aprovada a Plataforma Continental para além das 200 milhas. O artigo 4 do anexo II da CNUDM determina que o prazo para a apresentação desses pedidos era de 10 anos a partir da entrada em vigor da CNUDM, prazo venceria em 16 de novembro de 2004 (ZANELLA, 2017, p. 300).

Para que seja apresentada à Comissão de Limites da Plataforma Continental, a solicitação para ampliar a extensão das 200 milhas deve ser feita mediante estudo da respectiva área, de forma minuciosa.

Diante desse procedimento a ser seguido, o Brasil resolveu se antecipar e começou as pesquisas nas áreas para as quais pretendia solicitar a extensão, antes mesmo da entrada em vigor da CNUDM em 1994:

Em decorrência dessa necessidade, a CIRM elaborou o Plano de Levantamento da Plataforma Continental Brasileira (LEPLAC), que foi aprovado pelo Decreto n. 98.145, de 7 de março de 1988 e alterado pelo Decreto $\mathrm{n}$. 98.145, de 15 de setembro de 1989. [...] o Brasil, antecipando-se e levando em conta o prazo inicial de 10 anos, iniciou os estudos e levantamentos relativos a delimitação da plataforma continental (ZANELLA, 2017, p. 332).

E quanto as informações coletadas e o custo devido, explica Zanella:

As expedições da LEPLAC obtiveram dados sobre mais de $350 \mathrm{mil} \mathrm{km}$ de litoral nacional. Foram coletados dados batimétricos (por $90.707 \mathrm{~km}$ ), sísmicos (por $50.366 \mathrm{~km}$ ), gravimétricos (por $97.237 \mathrm{~km}$ ) e magnetométricos (por $93.604 \mathrm{~km}$ ) por toda extensão da plataforma brasileira. Para tal, foram dispendidos mais e US\$ 40 milhões, a cargo da Marinha (emprego de navios e execução do projeto) e da Petrobras (aquisição e processamento dos dados geofísicos) (ZANELLA, 2017, p. 333).

E para apresentar o respectivo projeto à CLPC com todas as informações coletadas, foi estruturado um modelo:

Conforme previsto no Modus Operandi para análise de uma submissão à CLPC, a proposta brasileira era composta de três documentos: o Executive Summary (um resumo do pedido); o Main Body (a parte analítica e descritiva) e o Supporting Scientific and Tecnical Data (com todos os dados mencionados na parte analítica) (ZANELLA, 2017, p. 334).

Assim, realizados todos esses levantamentos, em 17 de maio de 2004 o Brasil apresentou o projeto à Comissão de limites da Plataforma Continental (CLPC) e em 04 de abril de 2007 foi dado o parecer, que concedeu $81 \%$ do solicitado pelo Brasil, sendo que os 19\% não atendidos se referiam a quatro pontos: ao cone do Amazonas, à cadeia Norte Brasileira, à cadeia Vitória Trindade e à margem continental Sul. 
Os motivos que levaram a Comissão a não aprovar às respectivas áreas, foram as seguintes:

a) Cone do Amazonas - A Comissão não ficou convencida da localização da base do talude continental e, consequentemente, da posição do pé do talude. Trata-se de uma região que não se enquadra facilmente no modelo padrão de margem continental prevista na CNUDM. [...] Não há uma delimitação acentuada, com fácil distinção entre plataforma, talude e elevação. Em suma, a CLPC não concordou com a localização do pé do talude e a delimitação do limite exterior proposta pelo Brasil, entendendo que a base do talude no cone do Amazonas estaria em região menos profunda e mais próxima à costa.

b) Na cadeia Norte-Brasileira - A Comissão divergiu do entendimento brasileiro e entendeu que parte do pedido se situava na sobre elevação continental e nos fundos oceânicos. Desta forma, a CLPC concluiu que não se tratava de um prolongamento natural, posto que parte do requisitado não estava integrada ao talude na margem continental brasileira. c) Na cadeia Vitória-Trindade - [...] a CLPC declarou ter dúvidas se seria uma crista submarina, que permite a extensão da plataforma, ou se seria uma crista oceânica (na totalidade ou em partes), que não produziria direitos a extensão.

d) Na margem continental sul- a CLPC divergiu quanto as alterações realizadas pelo Brasil no Adendo, sobretudo nas áreas de platô de Santa Catarina e do cone do Rio Grande (ZANELLA, 2017 p.338/339/340)

E diante dos pontos não atendidos e das recomendações dadas pela CLPC, o Brasil resolveu por apresentar novamente a CLPC o projeto para a extensão da Plataforma Continental, realizando a pesquisa somente nas áreas que não foram atendidas no primeiro projeto:

Em 10 de abril de 2015 o Brasil apresentou nova submissão revisada em relação a margem continental sul. A estratégia brasileira foi de apresentar as submissões revisadas separadamente, levando em consideração as recomendações da CLPC em relação a cada região onde não houve a concordância da Comissão. Isto é, o Brasil, ainda irá apresentar suas submissões revisadas quanto as outras três regiões em que a CLPC divergiu do entendimento brasileiro e solicitou nova apresentação (ZANELLA, 2017, p. 340).

Em suma, a extensão da Plataforma Continental brasileira ainda está em processo de aprovação, visto que a Comissão de Limite da Plataforma Continental não aprovou por completo o pedido de ampliação da Plataforma brasileira em todos os pontos apresentados.

\section{CONSIDERAÇÕES FINAIS}

As discussões acerca do uso dos mares que precedeu a CNUDM foram diversas e longas, pois os Estados não entravam em um consenso, devido aos costumes já 
existentes, em consequência, a consolidação das leis demorou muito a ser elaborada, pois como explicado no início deste trabalho, já era de conhecimento de muitos Estados a importância da regulamentação, à princípio por motivos de navegação.

A consolidação da CNUDM foi um marco muito importante, visto ter estabelecido uma segurança quanto a jurisdição nacional de cada Estado Costeiro em um determinado espaço no oceano, e também garantir o direito de acesso ao mar para os Estados Sem Litoral, desta forma, vemos que um dos seus objetivos é garantir a igualdade de acesso aos recursos e rotas existentes no mar para todos.

Em meio à CNUDM, o estabelecimento das faixas marítimas foi muito importante, pois descreveu os direitos e deveres a serem exercidos pelo Estado Costeiro e a serem respeitados pelos demais Estados, pois a invasão de um Estado no espaço marítimo de jurisdição nacional de outro é um fato que ainda pode ocorrer nos tempos de hoje, bem como o ocorrido no Brasil.

Dentre as faixas marítimas, a Plataforma Continental Brasileira é uma faixa que pode ser estendida, assim, os direitos e deveres seriam também estendidos para além das 200 milhas marítimas, estando os recursos da área (que pode chegar em 350 milhas) sob o poderio brasileiro.

Ora, o projeto apresentando em 2004 não foi 100\% aprovado, visto alguns dados não estarem claros para a Comissão, dessa forma a partir das reflexões apontadas neste artigo entende-se que é válida a apresentação do segundo projeto referente às áreas pendentes de aprovação, depois com novas pesquisas, com informações mais claras e minuciosas, o respectivo direito poderá ser reconhecido pela Comissão.

\section{REFERENCIAS}

ACCIOLLY, Hildebrando; SILVA, Geraldo Eulálio do Nascimento e; CASELLA, Paulo Borba. Manual de Direito Internacional Público. 23. ed. São Paulo: Saraiva, 2017.

BARBOSA, Sérgio Ricardo Segovia. A Amazônia Azul: a sua gênese e a sua importância para o Brasil. 2012. 65 f. TCC (Graduação) - Curso de Altos Estudos de Política e Estratégia, Escola Superior de Guerra, Rio de Janeiro, 2012.

BARROS, José Fernando Cedeño de. Direito do mar e do meio ambiente. São Paulo: Aduaneiras, 2017.

CASTRO, Luiz Augusto de Araujo. O Brasil e o novo direito do mar: mar territorial e zona econômica exclusiva. Brasília: FUNAG, 1989.

CRETELLA NETO, José. Curso de Direito Internacional Público: A Sociedade Internacional. 4 ed. Lisboa: AAFDL, 1993.

MAZZUOLI, Valerio de Oliveira. Curso de Direito Internacional Público. 8. ed. São Paulo: Revista dos Tribunais, 2014. 
MENEZES, Wagner. O Direito do Mar. Brasília: Funag, 2015.

REZEK, Francisco. Direito Internacional Público. 17. ed. São Paulo: Saraiva, 2018.

TRINDADE, Antônio Augusto Cançado. A Nova Dimensão do Direito Internacional Público. Distrito Federal: Brasília. 2003.

VARELLA, Marcelo Dias. Direito Internacional Público. 6. ed. São Paulo: Saraiva, 2016.

ZANELLA, Tiago V. Manual de Direito do mar. Belo Horizonte: D’Plácido, 2017. 